\title{
Retention forces between primary and secondary CAD/CAM manufactured telescopic crowns: an in vitro comparison of common material combinations
}

\author{
Martin Schimmel ${ }^{1,2}$ - Moritz Walther ${ }^{1}$ - Nadin Al-Haj Husain ${ }^{1} \cdot$ Kensuke Igarashi $^{3}$ • Julia Wittneben ${ }^{1}$. \\ Samir Abou-Ayash ${ }^{4}$ (D)
}

Received: 25 January 2021 / Accepted: 29 March 2021 / Published online: 8 April 2021

(C) The Author(s) 2021

\begin{abstract}
Objectives To analyze the retention forces between primary and secondary telescopic crowns milled from various materials and to compare them with the retention forces between cast telescopic crowns made of precious metal alloys.

Materials and methods Primary and secondary crowns $(N=60 ; n=10$ per group) were fabricated using various material combinations (1: zirconia [ZIR]/polyether ether ketone [PEEK]; 2: titanium grade IV [TI]/PEEK; 3: PEEK/PEEK; 4: nonprecious alloy [NPA]/PEEK; 5:NPA/NPA), while precious alloy (PA) was used for the control group (6: PA/PA). The retention forces at 10,1000,5000, and 10,000 connection and disconnection cycles and the relative weights were analyzed, applying nonparametric repeated measures ANOVA and post hoc Mann-Whitney and Wilcoxon signed-rank tests $(\alpha<0.05)$.

Results Globally, significant differences in the retention forces among the materials $(p<0.0001)$, time points $(p<0.0001)$, and wear resistance for the various materials $(p<0.0001)$ were observed. No significant changes in retention forces compared to baseline were observed in groups $2,4,5$, and 6 . A significantly higher weight loss for both primary and secondary crowns was observed in groups 4 and 6.

Conclusions The material combination in telescopic attachments influences retention forces and wear. Interactions between materials and time were evident, indicating that the change in retention forces differs among the materials. The combinations of milled TI/PEEK and NPA/NPA qualify for further preclinical testing in a more clinically realistic setup, determining a material-specific double-crown design.

Clinical relevance The design of precious alloy telescopic crowns cannot be directly transferred to other milled material combinations due to different retention behaviors.
\end{abstract}

Keywords Alloy $\cdot$ PEEK $\cdot$ Retention force $\cdot$ Telescopic crown $\cdot$ Wear $\cdot$ Zirconia

Samir Abou-Ayash

samir.abou-ayash@zmk.unibe.ch

1 Department of Reconstructive Dentistry and Gerodontology, School of Dental Medicine, University of Bern, Bern, Switzerland

2 Division of Gerodontology and Removable Prosthodontics, University of Geneva, Geneva, Switzerland

3 Department of Dental Materials Science, School of Life Dentistry at Niigata, The Nippon Dental University, Niigata, Japan

4 Section for Digital Implant- and Reconstructive Dentistry [DIRecD], Department of Reconstructive Dentistry and Gerodontology, School of Dental Medicine, University of Bern, Freiburgstrasse 7, 3010 Bern, Switzerland

\section{Introduction}

In partially edentulous patients, removable partial dentures (RPDs) represent one of the available treatment options for replacing missing teeth, especially when multiple teeth or adherent structures such as hard and soft tissues must be replaced [1]. There are several RPD types, with clasp-retained RPDs being the most commonly applied type worldwide [2]. RPDs can successfully be combined with strategically placed implants, which might be of particular benefit in clinical situations with extended edentulous ridges. However, these toothimplant-retained RPDs usually compose multiple types of attachments on the abutment teeth and implants. Whether this combination of different attachments affects abutment survival or complication frequencies has not yet been conclusively 
clarified [3]. Double crowns can be used on both teeth and implants and therefore represent one option to overcome the use of mixed attachments in tooth-implant-supported RPDs. In general, reported abutment and prosthetic survival rates in double-crown-retained RPDs are higher compared to classical clasp-retained RPDs [4].

Double-crown attachments consist of a primary crown, which is directly cemented to an abutment tooth or screwed onto an implant, and a secondary crown, which is incorporated in the denture. Double crowns are frequently applied, especially in Japan and Germany [5-8]. Among the various types of double crowns, telescopic crowns with a parallel- or nearly parallelwalled $\left(0-2^{\circ}\right)$ primary crowns are commonly applied [9].

Typically, the combination of materials in telescopiccrown-retained RPDs composes a metal-metal, zirconia-met$\mathrm{al}$, or metal-polymer contact, which has different surface wear patterns and, therefore, variable resistance to repetitive removal-insertion cycles $[9,10]$. Commonly, a hard material that shows high resistance to wear was chosen as the primary crown and a more flexible material as the secondary crown. Historically, primary and secondary crowns were cast from precious or non-precious metal alloys [4]. The timeconsuming casting techniques, especially in combination with the use of precious alloys, resulted in high manufacturing costs and consequently in high prices relative to claspretained RPDs. Furthermore, the casting of non-precious alloys is a challenging procedure, resulting in varying alloy compositions, surface properties, and consequently different levels of biocompatibility [11]. With the advent of computeraided design (CAD) and computer-aided manufacturing (CAM) technologies, precision milling of inner and outer crowns has been more and more frequently applied. Consequently, further materials for primary and secondary crowns including zirconia $\left(\mathrm{ZrO}_{2}\right)$, titanium, or high-strength resins such as polyether ether ketone (PEEK) [12-16] have been introduced. Milling primary and secondary crowns from these materials may help reduce human labor and manufacturing costs, and the related financial burden for the patient, of double-crown-retained RPDs [17]. Furthermore, only a single study which has systematically evaluated the evolution of retention forces using various material combinations, especially regarding milled primary and secondary crowns, could be identified [18]. Therefore, the current study aimed to analyze the progression over time of retention forces of various material combinations in milled primary and secondary crowns and to compare it to the golden standard (cast precious alloy primary and secondary crowns) with the same design. The null hypothesis was that the retention forces of various milled primary and secondary crowns will be equal to those of casting precious alloy crowns after 10,000 connection and disconnection cycles, simulating 10 years of use. Furthermore, the loss of mass after the simulated 10-year use was to be measured as a secondary outcome.

\section{Materials and methods}

\section{Specimen preparation}

A total of 1 control and 5 test groups containing 10 specimens each $(n=10)$ were defined, resulting in a total of 60 specimens. The primary crowns of the test groups were made of a non-precious alloy (NPA), zirconia (ZIR), polyether ether ketone (PEEK), or titanium (TI). The secondary crowns were made of NPA or PEEK. Primary and secondary crowns made out of a precious alloy (PA) served as the control group. The specifications of the applied materials and their combinations are given in Tables 1 and 2.

An artificial typodont (FDI 13, Nissin, Kyoto, Japan) was prepared for a full crown according to the following design: a shoulder of $1.2 \mathrm{~mm}$, axial reduction of $1.2 \mathrm{~mm}$, an axial taper of $6^{\circ}$, and incisal clearance resulting in a final height of $5 \mathrm{~mm}$. Afterward, the prepared tooth was digitized with a laboratory scanner (DW Series 7, Dentalwings, Chemnitz, Germany) and milled (M1; Zirkonzahn, Gais Italy) from polyurethane resin (Try-in III; Zirkonzahn, Gais, Italy) $(n=60)$. The bottom of the tooth had an oval shape with one flattened surface, guaranteeing precise repositioning in a customized device for standardized base plate manufacturing and subsequent luting of the primary crowns to the artificial teeth (Fig. 1). The teeth were embedded in polymethyl methacrylate (PMMA) (Paladur ${ }^{\circledR}$; Kulzer GmbH, Hanau, Germany) resin base plates.

\section{Milling procedure}

CAD was used for the primary and secondary crowns of the test groups. Subsequently, all crowns were milled using standardized parameters on the same milling machine (DC5; Dental Concept Systems GmbH, Ulm, Germany): a cement gap of $0.02 \mathrm{~mm}$, a horizontal crown border offset of $0.1 \mathrm{~mm}$, and a vertical offset of $0 \mathrm{~mm}$. The wall thickness of all primary and secondary crowns was $0.3 \mathrm{~mm}$ to evaluate if all crowns would survive the cyclic connections and disconnection despite their small wall thickness. The retention height was $4.5 \mathrm{~mm}$ interdentally and $2 \mathrm{~mm}$ buccally/orally, and the taper was $1^{\circ}$. The outer surface of the primary crowns was finished by manual polishing without additional grinding. The polishing was done, following material-specific polishing tools, always by the same master dental technician (Table 3). The inner surface of the secondary crowns was not modified. For the control group, the primary crowns were milled from wax with the same parameters applied to the test groups and subsequently converted to PA crowns using the lost-wax technique. After polishing, the secondary crowns were manually created from wax, copying the digital design of the secondary crowns as well as possible, and subsequently also cast from the same PA. An overview of all types of primary and 
Table 1 Overview and composition of applied materials. PA, precious alloy; NPA, non-precious alloy; PEEK, polyether ether ketone; TI, titanium; ZIR, zirconia

\begin{tabular}{llll}
\hline Material & Brand name & Manufacturer & Composition \\
\hline ZIR & DC Zirkon Premium & Dental Concepts Systems GmbH, Wahlsburg, Germany & Titanium: $>99 \%$ \\
TI & DC Titan Grade 4 & Dental Concepts Systems GmbH, Wahlsburg, Germany & Others: $<1 \%$ \\
& & Polyether ether ketone: $80 \%$ \\
PEEK & BioHPP & Bredent Group, Senden, Germany & Inorganic fillers: $20 \%$ \\
NPA & DC NP EXPERT C+B 270 & Dental Concepts Systems GmbH, Wahlsburg, Germany & Cobalt: $65 \%$ \\
& & & Chrome: $28.5 \%$ \\
& & & Molybdenum: $5.5 \%$ \\
PA & Cendres Metaux, Biel/Bienne, Switzerland & Others: $<1 \%$ \\
& & & Gold: $68.6 \%$ \\
& & & Platinum: $2.45 \%$ \\
& & & Palladium: $3.95 \%$ \\
& & Silver: $11.85 \%$ \\
Protor 3 & & Copper: $10.6 \%$ \\
\end{tabular}

secondary crowns is presented in Fig. 2. A tertiary structure was designed based on the secondary crown design and milled from a non-precious alloy. The design covered the secondary crowns completely to prevent bending during cyclic loading and included a direct connection to the collet of the test device (Model 5942; Instron France SAS, Elancourt, France).

\section{Crown conditioning and cementation}

The inner surfaces of the primary crowns and the tertiary structure, as well as the outer surfaces of the secondary crowns, were sandblasted with aluminum oxide ( 3 bar pressure, grain size $50 \mu \mathrm{m}$ ), creating a micro-rough surface. Thereafter, all specimens were placed in an ultrasonic bath for $5 \mathrm{~min}$ and, following air drying, weighed on a balance with a precision of $1 \mu \mathrm{g}$ (R200D; Sartorius AG, Göttingen, Germany).

The primary crowns were luted to the artificial polyurethane teeth using a chemically polymerizing PMMA

Table 2 Applied material combinations for the fabrication of primary and secondary crowns. $P A$, precious alloy; $N P A$, non-precious alloy; PEEK, polyether ether ketone; TI, titanium; ZIR, zirconia

\begin{tabular}{lll}
\hline & Primary inner crown & Secondary outer crown \\
\hline Test $1(n=10)$ & ZIR & PEEK \\
Test $2(n=10)$ & Ti & PEEK \\
Test $3(n=10)$ & PEEK & PEEK \\
Test $4(n=10)$ & NPA & PEEK \\
Test $5(n=10)$ & NPA & NPA \\
Control $(n=10)$ & PA & PA \\
\hline
\end{tabular}

(Paladur®). After polymerization, the base plates, including the specimens with the primary crowns, were mounted in the test device, and the secondary crowns were placed on the primary crowns in their final position. The base plate mounts of the test device were identical to those of the customized base plate manufacturing device, guaranteeing exact specimen repositioning (Fig. 3). The tertiary structure was filled with

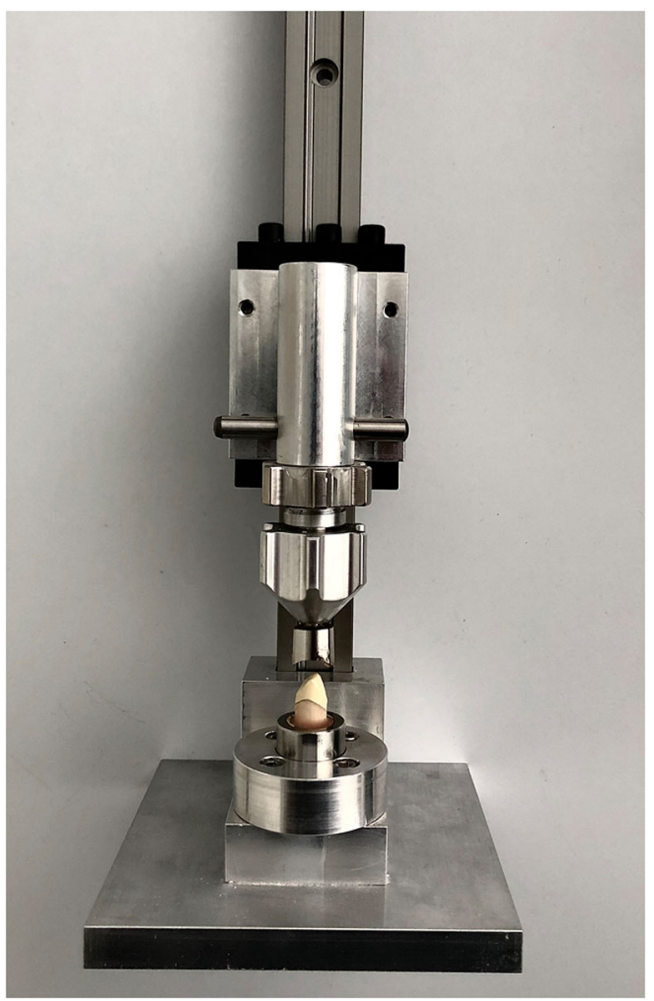

Fig. 1 Customized device for standardized base plate fabrication for the artificial tooth and cementing of the primary crown 
Table 3 Overview of the material-specific polishing steps and instruments. All instruments were from Fa. Bredent, Senden, Germany. NPA, non-precious alloy; TI, titanium; PEEK, polyether ether ketone; $Z I R$, zirconia

\begin{tabular}{llll}
\hline & NPA/TI & PEEK & ZIR \\
\hline Step 1 & Ceragum Gummipolierwalze & Ceragum Gummipolierwalze & Rundbürsten Ziegenhaar \\
& REF PWKGO600 & REF PWKGO600 & REF 35000540 \\
Step 2 & Rundbürsten Chungking & Rundbürsten Ziegenhaar & Zi-polish \\
& REF 35000510 & REF 35000540 & REF 36010025 \\
Step 3 & Abraso Starglanz & Lederschwabbel & \\
& REF 52000163 & REF 35000660 & \\
Step 4 & & Abraso Starglanz & \\
& & REF 52000163 & \\
\hline
\end{tabular}

chemically polymerizing PMMA resin (Paladur®), fixated in the top collet of the measuring device, and moved downwards until the secondary crown was completely covered. After the polymerization process, the top collet, including the tertiary structure with the secondary crown, was moved upwards, and all excess resin was removed.

\section{Cyclic loading}

Cyclic connections and disconnections were performed 10,000 times, simulating 10 years of use, assuming denture insertion and removal three times a day. The cycles were performed under wet conditions (distilled water) at a temperature of $37^{\circ} \mathrm{C}$ in a temperature-controlled bath. The crosshead speed was set to $1 \mathrm{~mm} / \mathrm{s}$ while moving downward and 0.5 $\mathrm{mm} / \mathrm{s}$ while moving upward. The secondary crowns were connected to the primary crowns with a force of $40 \mathrm{~N}$, which was held for $1 \mathrm{~s}$. The secondary crowns were then disconnected, and the maximum forces during disconnection were recorded in Newtons $(\mathrm{N})$ by the test device. The vertical distance for each cycle was $3 \mathrm{~mm}$. For the subsequent analyses, the maximum disconnection forces of cycles 10, 100, 500, 1000, 2000, 3000, 4000, 5000, 6000, 7000, 8000, 9000, and 10,000 were considered, but the data of every cycle were recorded. Data from the first 10 cycles were omitted to ensure stable testing conditions for all specimens. After finishing the cyclic connections, the primary and secondary crowns were removed from the specimens and the tertiary structure, respectively, using a Bunsen burner. All PMMA remnants on the crowns were carefully removed at 3.5-fold magnification, and the weight was assessed using the same high precision balance from the start of the experiment.

\section{Statistical analysis}

A power analysis could not be performed due to the absence of reference data. Nevertheless, a higher sample size $(n=10$ per group) relative to similar in vitro studies on double crowns was chosen [19-21]. For assessing the outcome of variable retention and wear (relative weight loss), a nonparametric, repeated measures ANOVA by Brunner and Langer [22], with the factors time (number of cycles, as repeated measurements) and material, was performed. Post hoc exact Mann-Whitney tests were performed to compare the retention forces and weight losses of all materials with each other after 10, 1000, 5000, and 10,000 loading cycles simulating baseline, 1, 5, and 10 years of use, respectively. Effect values for materials were estimated as the median difference (including 95\% confidence intervals [CIs]) with respect to the baseline category PA/PA (control). To assess changes in retention forces over time within each material, exact Wilcoxon signed-rank tests were performed. Here, the effect values for cycles were estimated by the Hodges-Lehmann median (including 95\% CIs) with respect to the baseline category of 10 loading cycles. To compare the behavior over time between each pair of materials, nonparametric repeated-measures ANOVAs were again utilized. Throughout the analysis, $p$ values smaller than 0.05

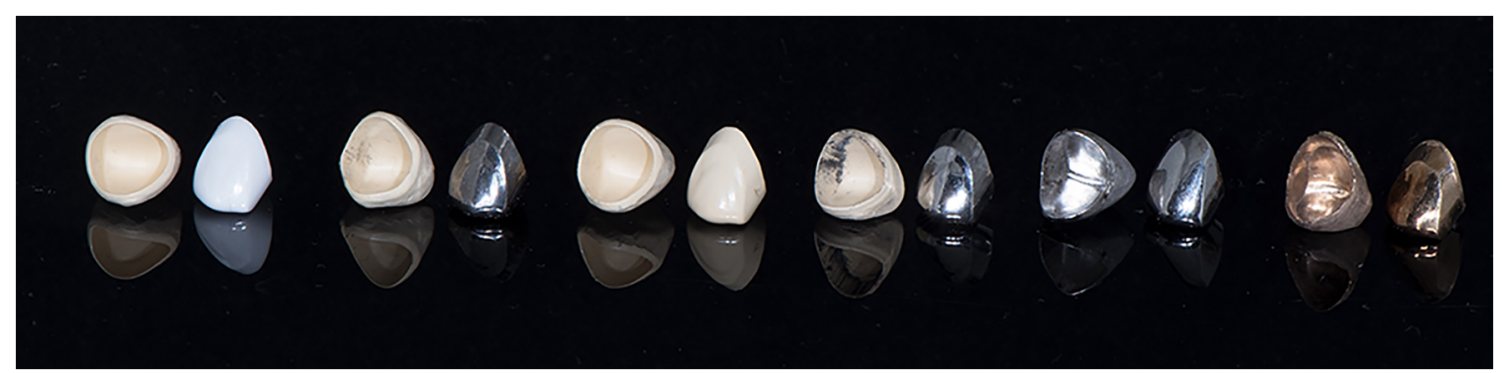

Fig. 2 All types of primary and secondary crowns, from left to right: Zirconia/PEEK, non-precious alloy/PEEK, PEEK/PEEK, titanium/PEEK, nonprecious alloy/non-precious alloy, and precious alloy/precious alloy 


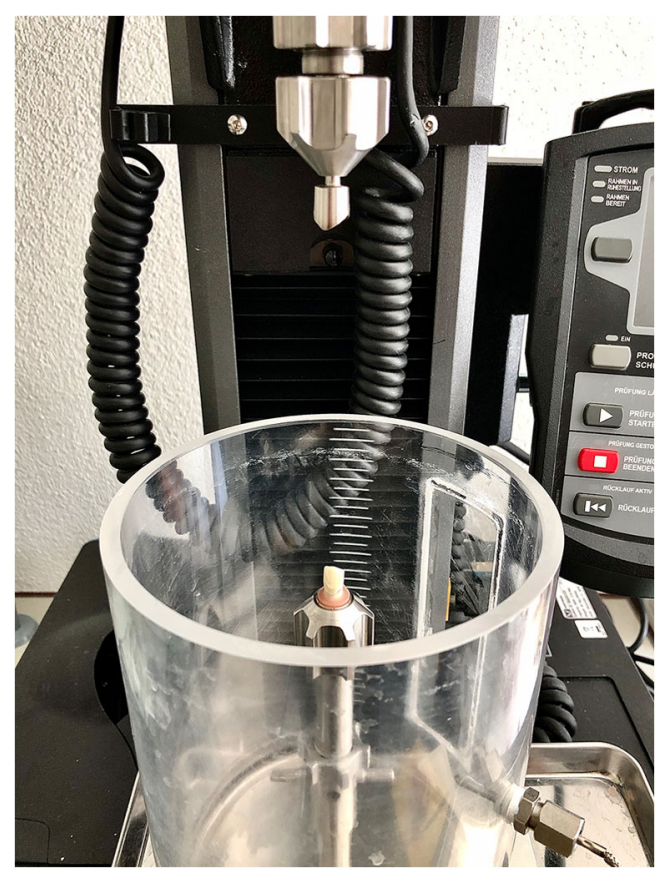

Fig. 3 Specimen positioning with the cemented primary crown in the test device before luting of the secondary crown in the tertiary structure, which was positioned in the upper collet

were considered statistically significant. All analyses were performed with the statistics software $\mathrm{R}$ version 3.5.0 [23].

\section{Results}

No fractures or decementations were observed during the procedure. Materials and loading cycles showed significant impacts on both retention force and relative weight loss (all $p<$ 0.0001 ), including significant interaction (all $p<0.0001$ ) according to the repeated measures nonparametric ANOVA.

\section{Evolution of retention forces within the groups}

An overview of the retention forces during all cycles is depicted in Fig. 4. All materials were evaluated separately, comparing the retention forces at the beginning and the end of six cycling intervals: the initial year of use (I) $=$ cycle $10 \mathrm{vs}$. 1000; the initial 5 years of use (II) $=$ cycle 10 vs. 5000 ; the initial 10 years of use $(\mathrm{III})=$ cycle 10 vs. 10,000 ; the second to the fifth year of use (IV) $=$ cycle $1000 \mathrm{vs.} 5000$; the second to the tenth year of use $(\mathrm{V})=$ cycle $1000 \mathrm{vs.} 10,000$; and the sixth to the tenth year of use $(\mathrm{VI})=$ cycle 5000 vs. 10,000 .

A statistically significant increase in retention forces was observed for test group 1 (ZIR/PEEK) for all intervals (I-V: $p$ $=0.002 ; \mathrm{VI}: p=0.004)$. As for test group 2 (TI/PEEK), the intervals I $(p=0.01)$ and II $(p=0.02)$ showed increases, whereas a significant decrease of retention forces was found over interval V $(p=0.04)$. In test group 3 (PEEK/PEEK), retention forces rose significantly over all intervals except intervals V and VI (I-III: $p=0.002$; IV: $p=0.004$ ). Significant differences could be found for test group 4 (NPA/PEEK) in the intervals IV $(p=0.01), \mathrm{V}(p=0.004)$, and VI $(p=0.03)$, strictly decreasing after 1000 cycles. For test groups 5 (NPA/NPA) and 6 (PA/PA), only one interval presented a significant decrease in retention force over time. In group 5 (NPA/NPA), this was interval IV $(p=0.049)$; and in group $6(\mathrm{PA} / \mathrm{PA})$, it was interval VI $(p=0.008)$. Table 4 lists an overview of the estimated differences between baseline and 1000,5000 , and 10,000 cycles, including 95\% confidence intervals (CIs) and separated for all materials.

\section{Evolution of retention forces across the groups}

With respect to the parameter "material," significant differences of all cumulative loading cycles were found when the control group (PA/PA) was compared to groups 1 (ZIR/ PEEK) and 3 (PEEK/PEEK) $(p<0.001)$. Comparisons between the control group and groups 2 (TI/PEEK, $p=0.15$ ), 4 (NPA/PEEK; $p=0.47$ ), and 5 (NPA/NPA, $p=0.06$ ) revealed no statistically significant differences, demonstrating similar evolution of retention forces. An overview of retention force differences at 10,1000,5000, and 10,000 cycles, comparing the test groups to the control group, is presented in Table 5.

\section{Wear}

Wear was evaluated by the relative weight loss of the primary and secondary crowns during 10,000 connection and disconnection cycles. The weighing of each primary and secondary crown was performed before and after the cyclic loading. Figure 5 provides an overview of the relative weight loss of the primary and secondary crowns. The highest relative weight loss was found in groups 4 (NPA/PEEK) and 6 (PA/ PA). However, comparing the control to the test groups, this loss was not significant for group 4 (for which we observed the greatest change in weight across all groups), neither in the primary $(p=1)$ nor in the secondary crowns $(p=0.12)$.

\section{Discussion}

The current study compared the evolution of retention forces between primary and secondary telescopic crowns milled from various materials to the retention forces of cast precious metal alloy primary and secondary crowns, simulating 10 years of denture insertion and removal. Based on our observations, the null hypothesis of equal retention forces was rejected. Statistically significant differences for the parameters' material, cycling, interaction, and wear could be demonstrated. 
Median Retention Forces and IQR for different Materials over Time



Fig. 4 Change of retention forces for each material combination over time. "No. of Cycles" refers to the number of insertion-separation cycles; retention was consecutively tested for $10-10,000$ cycles. PA $=$ precious alloy, NPA $=$ non-precious alloy, PEEK $=$ polyether ether ketone, $\mathrm{TI}=$ titanium, and ZIR = zirconia

limitation of our approach is that horizontal and extra-axial forces, which are known to accelerate wear behavior, were not applied [28]. In addition, both the primary and secondary crowns were fabricated with lower material layer thicknesses than described in the literature [19-21]. The idea behind this was to evaluate whether these new material combinations would survive 10 years of simulated insertion and removal even in these reduced layer thicknesses and thus potentially eliminate one of the main limitations of double crowns, which is over contouring [29]. Since no major damage to the crowns was observed, it is unlikely that the thin layer thicknesses had any effect on the retention forces due to the complete coverage of the crowns in a tertiary framework and the associated prevention of bending up.

Retention forces have been tested under moist conditions in previous studies on telescopic crowns. The moist conditions are necessary to generate hydraulic adhesion between primary and secondary crowns [30]. Both distilled water [31] and artificial saliva [32] have been used in previous studies to create a moist environment. Our preliminary tests showed no 
Table 4 Overview of significantly different retention forces between applied material combinations at specific loading cycles. $P A$, precious alloy; $N P A$, non-precious alloy; PEEK, polyether ether ketone, $T I$, titanium; ZIR, zirconia

\begin{tabular}{|c|c|c|c|}
\hline Number of loading cycles & Material combination 1 & Material combination 2 & $p$ value \\
\hline \multirow[t]{10}{*}{10} & $\mathrm{PA} / \mathrm{PA}$ & NPA/NPA & $<0.0001$ \\
\hline & $\mathrm{PA} / \mathrm{PA}$ & PEEK/PEEK & 0.009 \\
\hline & $\mathrm{PA} / \mathrm{PA}$ & ZIR/PEEK & $<0.0001$ \\
\hline & NPA/NPA & NPA/PEEK & 0.0002 \\
\hline & NPA/NPA & PEEK/PEEK & $<0.0001$ \\
\hline & NPA/NPA & TI/PEEK & 0.0007 \\
\hline & NPA/NPA & ZIR/PEEK & $<0.0001$ \\
\hline & NPA/PEEK & ZIR/PEEK & 0.006 \\
\hline & PEEK/PEEK & ZIR/PEEK & 0.004 \\
\hline & TI/PEEK & ZIR/PEEK & 0.0007 \\
\hline \multirow[t]{9}{*}{1000} & $\mathrm{PA} / \mathrm{PA}$ & NPA/NPA & 0.003 \\
\hline & $\mathrm{PA} / \mathrm{PA}$ & ZIR/PEEK & 0.004 \\
\hline & NPA/NPA & NPA/PEEK & $<0.0001$ \\
\hline & NPA/NPA & PEEK/PEEK & 0.0007 \\
\hline & NPA/NPA & TI/PEEK & 0.03 \\
\hline & NPA/NPA & ZIR/PEEK & $<0.0001$ \\
\hline & NPA/PEEK & TI/PEEK & 0.01 \\
\hline & PEEK/PEEK & ZIR/PEEK & 0.009 \\
\hline & TI/PEEK & ZIR/PEEK & 0.0005 \\
\hline \multirow[t]{8}{*}{5000} & $\mathrm{PA} / \mathrm{PA}$ & NPA/NPA & 0.006 \\
\hline & $\mathrm{PA} / \mathrm{PA}$ & ZIR/PEEK & 0.045 \\
\hline & NPA/NPA & NPA/PEEK & $<0.0001$ \\
\hline & NPA/NPA & ZIR/PEEK & 0.0001 \\
\hline & NPA/PEEK & PEEK/PEEK & 0.003 \\
\hline & NPA/PEEK & TI/PEEK & 0.0007 \\
\hline & PEEK/PEEK & ZIR/PEEK & 0.002 \\
\hline & TI/PEEK & ZIR/PEEK & 0.01 \\
\hline \multirow[t]{6}{*}{10,000} & $\mathrm{PA} / \mathrm{PA}$ & NPA/NPA & 0.002 \\
\hline & NPA/NPA & NPA/PEEK & $<0.0001$ \\
\hline & NPA/NPA & PEEK/PEEK & 0.045 \\
\hline & NPA/NPA & ZIR/PEEK & 0.005 \\
\hline & NPA/PEEK & PEEK/PEEK & 0.0001 \\
\hline & NPA/PEEK & TI/PEEK & 0.003 \\
\hline
\end{tabular}

difference between the two media; therefore, we decided to use distilled water for simplicity. Cyclic loading under wet conditions enables the formation of negative pressure in the occlusal gap while loosening the secondary crown. The compensation occurs via a delayed salivary flow (here, distilled water) in the area of the parallel surfaces between the primary and secondary crowns. The resulting flow resistance (HagenPoiseuille law) between the contact surfaces increases the adhesion, especially in very thin capillary-like gaps, such as can be found between the primary and secondary crowns due to the CAD/CAM milling process [33]. This may explain why the retention forces in this study are significantly higher than the $5-10 \mathrm{~N}$ described as ideal in the literature, especially considering that the retention forces in the control group were in a similar high range. Such comparatively high retention forces have also been demonstrated in previous in vitro studies on retention forces under moist conditions [19, 31]. Using the present telescopic-crown materials under in vivo conditions, the retention forces should be tested intraorally, and if exceeding the desired forces, manual polishing of the primary crowns' outer and/ or secondary crowns' inner surfaces may be applied. Furthermore, increasing the offset between primary and secondary crowns, increasing the taper, or reducing the length of the retentive portions may represent further options during the $\mathrm{CAD} / \mathrm{CAM}$ process to decrease retention forces [19-21, 32, 34].

All applied materials demonstrated a significant change in retention force over at least one of the evaluated time intervals. 
Table 5 Overview of differences in the weight loss of primary and secondary crowns comparing all applied materials. $P A$, precious alloy; $N P A$, non-precious alloy; PEEK, polyether ether ketone; TI, titanium; ZIR, zirconia

\begin{tabular}{llll}
\hline Material combination 1 & Material combination 2 & $\begin{array}{l}p \text { value } \\
\text { "Primary" }\end{array}$ & $\begin{array}{l}p \text { value } \\
\text { "Secondary" }\end{array}$ \\
\hline PA/PA & NPA/NPA & $<0.0001$ & $<0.0001$ \\
PA/PA & NPA/PEEK & 1 & 0.12 \\
PA/PA & PEEK/PEEK & $<0.0001$ & 0.001 \\
PA/PA & TI/PEEK & $<0.0001$ & $<0.0001$ \\
PA/PA & ZIR/PEEK & $<0.0001$ & 0.001 \\
NPA/NPA & NPA/PEEK & 0.014 & $<0.0001$ \\
NPA/NPA & PEEK/PEEK & 0.053 & 0.005 \\
NPA/NPA & TI/PEEK & 0.66 & 0.02 \\
NPA/NPA & ZIR/PEEK & 0.06 & 0.91 \\
NP/PEEK & PEEK/PEEK & 0.008 & 0.0001 \\
NP/PEEK & TI/PEEK & 0.01 & $<0.0001$ \\
NPA/PEEK & ZIR/PEEK & 0.008 & $<0.0001$ \\
NPA/PEEK & TI/PEEK & 0.48 & 0.54 \\
PEEK/PEEK & ZIR/PEEK & 0.53 & 0.02 \\
TI/PEEK & ZIR/PEEK & 0.55 & 0.04 \\
\hline
\end{tabular}

However, after ten simulated years of denture insertion and removal, no significant changes in retention forces relative to baseline were observed in groups 2 (TI/PEEK), 4 (NPA/ PEEK), 5 (NPA/NPA), and 6 (PA/PA). The retention forces in group 1 (ZI/PEEK) increased constantly and significantly over the entire study period, whereas the retention forces in group 3 (PEEK/PEEK) increased only during the first five simulated years, remaining constant thereafter. The only two groups that demonstrated significantly higher retention forces after 10 years were those which did not include a metal alloy primary crown. In general, an increase in retention forces is often seen in the early stages of testing various retentive elements for prostheses. This is attributed to initial plastic deformation and an increase in surface roughness [21, 35]. The outer surfaces of the primary crowns and the inner surfaces of the secondary crowns are prone to elastically reversible deformations and plastically irreversible deformations during insertion, removal, and chewing movements. Consequently, a possible explanation for these developments of the retention forces could be material-specific deformation or wear. In general, it can be assumed that an increase in roughness leads to an increase in retention force. In addition, the mechanical adaptation of the primary and secondary crowns at their interfaces may play a role in the increase [31]. However, this increase in retention force only continues until a critical limit of plastic deformation of at least one of the two crowns is reached. If this limit is exceeded, this leads to a decrease in the retention force since the interface between the primary and secondary crowns is no longer congruent and the desired static friction can no longer occur. The fact that the two groups in which retention forces increased were among the groups with the lowest relative weight loss supports the theory that material wear in these groups did not reach the critical limit to precipitate a decrease in retention force.

At the beginning (10 cycles) and at the end of the cyclic connections and disconnections (10,000 cycles), significantly different retention forces between most of the material groups were observed, which was also demonstrated in a previous study applying similar material combinations [31]. Comparing the evolution of retention forces, no significant differences between the control group and group 2 (TI/ PEEK, 4 (NPA/PEEK) or 6 (NPA/NPA) were found, which means that all groups including at least one metal part demonstrated similar retention behavior. Since the material combination PA/PA has been shown to be reliable, it seems advantageous to retain at least one metallic component in any possible material combination for telescopic crowns. Creating an optimum surface morphology using CAD (in addition to the precision of the milling process), the selected fit parameters, ideal tools, and the milling path strategy are decisive [15]. An improved fit with a consequently narrower joint gap between the primary and secondary crowns may be achieved using digital fabrication technologies. However, the knowledge regarding how an increased fit between primary and secondary crowns using different materials affects the development of retention forces, as well as the wear resistance, is very limited. Our results show that both the retention behavior and the wear were very different despite the standardized design of the primary and secondary crowns. The consequences of this could be that for each material combination, the optimal design must be separately determined and that earlier results on precious metal telescopic crowns cannot simply be transferred to these new material combinations. 
Fig. 5 a Relative weight loss (\%) in primary crowns in all applied material combinations; $\mathrm{PA}=$ precious alloy, NPA $=$ nonprecious alloy, PEEK = polyether ether ketone, $\mathrm{TI}=$ titanium, and $\mathrm{ZIR}=$ zirconia. Alphabetic superscripts indicate significant differences between the groups. b Relative weight loss (\%) in secondary crowns in all applied material combinations; $\mathrm{PA}=$ precious alloy, NPA = non-precious alloy, PEEK = polyether ether ketone, $\mathrm{TI}=$ titanium, and $\mathrm{ZIR}=$ zirconia. Alphabetic superscripts indicate significant differences between the groups
Relative Weight Loss after 10'000 Cycles

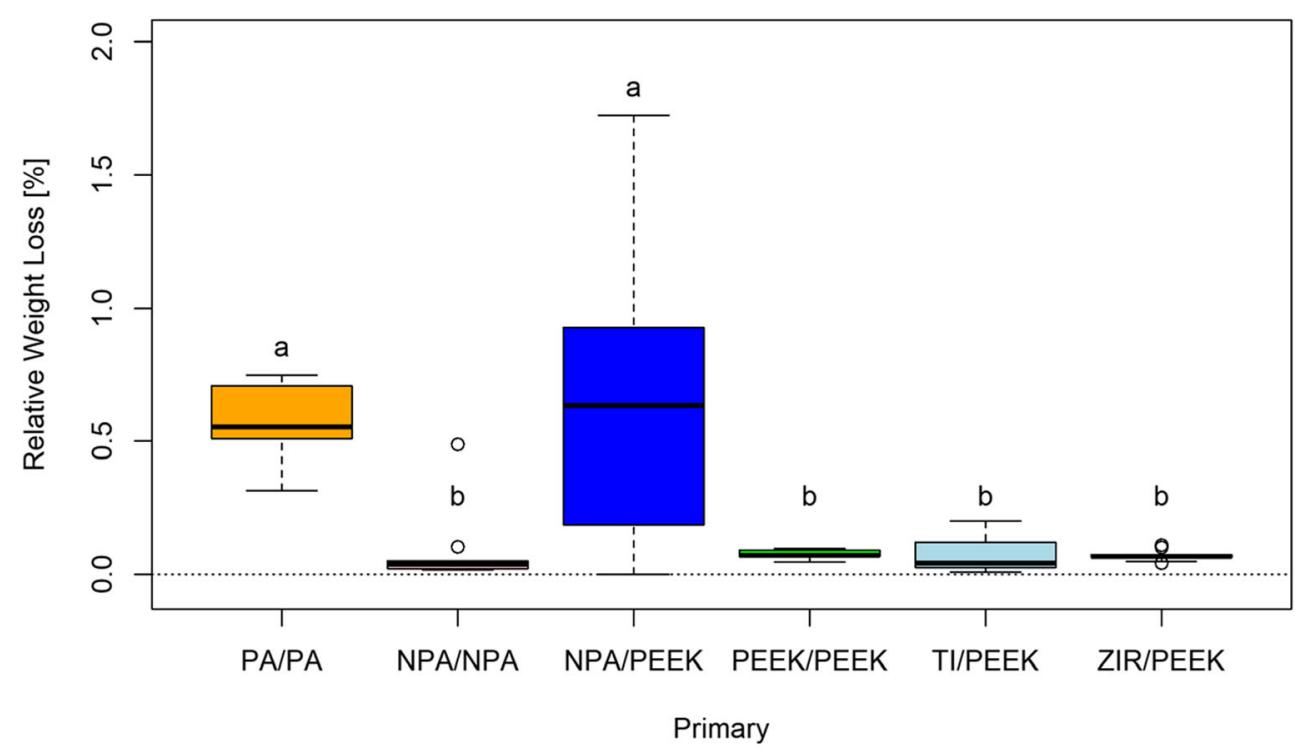

b

Relative Weight Loss after 10'000 Cycles

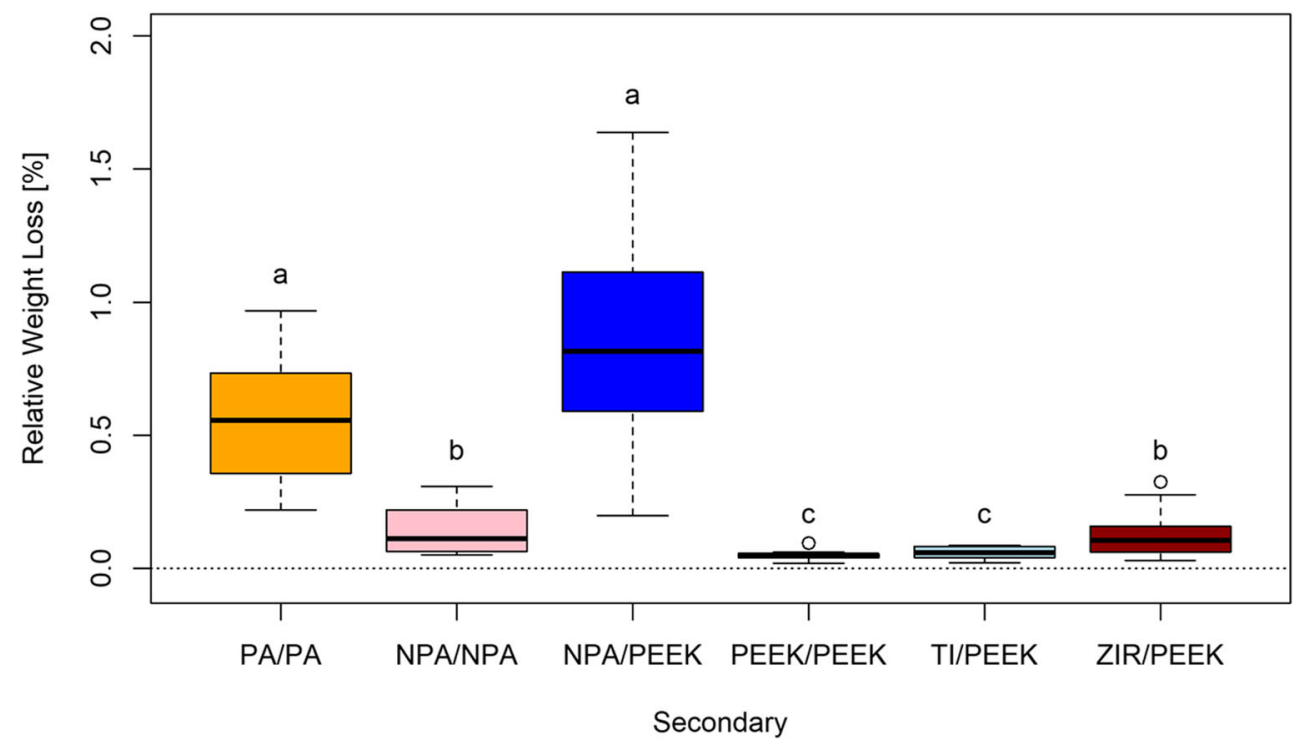

Wear of the secondary and especially primary telescopic crowns presents a major challenge for clinicians. While secondary crowns may be replaced with relative ease, replacing primary crowns on teeth requires the destruction of the crown, which is accompanied by potential damage to the remaining tooth structure. Therefore, one of the main requirements for double-crown systems is to choose a wear-resistant material, especially for the primary, but also for the secondary telescopic crown. In terms of wear resistance, the material combinations NPA/NPA, ZIR/PEEK, PEEK/PEEK, and TI/PEEK demonstrated more favorable outcomes relative to the control group. While ZIR/PEEK and PEEK/PEEK showed a constant increase in retention forces, the evolution of retention forces in the material combinations TI/PEEK and NPA/NPA were similar to the control group and may therefore be recommended for clinical application. The suitability of these material combinations has already been demonstrated in previous in vitro studies, with two (NPA/NPA) or four telescopic crowns (TI/ PEEK) per denture, respectively $[9,31]$. Although a significant decrease of retention forces $(36.17 \%)$ has been reported for casted NPA/NPA telescopic crowns after simulated 10 years of use, a recent in vitro study demonstrated a significantly lower loss of retention in milled compared to casted NPA/ NPA double crowns, confirming the results of the present study [18]. The difference between the casted and milled groups was mainly attributed to the higher accuracy and the 
lower surface roughness of the milled group [18]. The material combination NPA/NPA has also been evaluated in a retrospective clinical study and while the authors of that study did not observe a difference in denture survival, the abutment survival rate was significantly higher in the control group using PA/PA telescopic crowns [36]. However, the manufacturing technique of the NPA/NPA crowns has not been reported in that specific study.

Future in vitro studies should evaluate the effects of various designs, such as the taper or the gap size between primary and secondary crowns milled from promising, wear-resistant material combinations, e.g., TI/PEEK. The evolution of retention forces in such studies should be evaluated in a clinically more relevant setup with four telescopic crowns in a strategically beneficial distribution across the jaw. Furthermore, in addition to retention forces, other potential problems, such as the cementation of these new materials or the development of surface roughness due to wear and associated plaque adhesiveness, need to be investigated $[18,37]$. The results of those in vitro studies should be completed by in vivo studies focusing specifically on abutment survival.

\section{Conclusion}

The materials used for milling primary and secondary telescopic crowns have an effect on the absolute retention forces, the evolution of retention forces over time, and the resistance to wear, even if the same crown design is chosen. The material combinations titanium/PEEK and non-precious alloy/nonprecious alloy can be recommended for future research. The evolution of retention forces with these combinations was comparable to precious alloy/precious alloy telescopic crowns, but the wear was even smaller. The existing knowledge regarding telescopic crowns consisting of precious metal alloy primary and secondary crowns cannot be directly transferred to other material combinations, even if the same design is used for crown fabrication.

Acknowledgements The authors thank Leona Knüsel and Lukas Martig from signifcantis $\mathrm{GmbH}$, Bern, for the statistical analyses.

Funding Open Access funding provided by Universität Bern. The testing device for the cyclic connections and disconnections was funded by the research funds of the Swiss Dental Association (SSO). All milled specimens were manufactured and provided by Bredent.

\section{Declarations}

Ethical approval For this type of study, ethical approval was not required.

Conflict of interest The authors declare no competing interests.
Open Access This article is licensed under a Creative Commons Attribution 4.0 International License, which permits use, sharing, adaptation, distribution and reproduction in any medium or format, as long as you give appropriate credit to the original author(s) and the source, provide a link to the Creative Commons licence, and indicate if changes were made. The images or other third party material in this article are included in the article's Creative Commons licence, unless indicated otherwise in a credit line to the material. If material is not included in the article's Creative Commons licence and your intended use is not permitted by statutory regulation or exceeds the permitted use, you will need to obtain permission directly from the copyright holder. To view a copy of this licence, visit http://creativecommons.org/licenses/by/4.0/.

\section{References}

1. Bohnenkamp DM (2014) Removable partial dentures: clinical concepts. Dent Clin N Am 58:69-89

2. Campell SD, Cooper L, Craddock H, Hyde TP, Nattress B, Pavitt SH, Seymour DW Removable partial dentures: the clinical need for innovation. J Prosthet Dent 118:273-280

3. Melilli D, Davì G, Messina P, Scardina GA (2017) Tooth-implant connection in removable denture. A review. Minerva Stomatol 66: $35-42$

4. Wagner B, Kern M (2000) Clinical evaluation of removable partial dentures 10 years after insertion: success rates, hygienic problems, and technical failures. Clin Oral Investig 4:74-80

5. Bayer S, Steinheuser D, Grüner M, Keilig L, Enkling N, Stark H, Mues S (2009) Comparative study of four retentive anchor systems for implant supported overdentures - retention force changes. Gerodontology 26:268-272

6. Hakkoum MA, Wazir G (2018) Telescopic denture. Open Dent J $12: 246-254$

7. Stancis I, Jelenkovic A (2008) Retention of telescopic denture in elderly patients with maximum partially edentulous arch. Gerodontology 25:162-167

8. Weaver JD (1989) Telescopic copings in restorative dentistry. J Prosthet Dent 61:429-433

9. Arnold C, Hey J, Setz JM, Boeckler AF, Schweyen R (2018) Retention force of removable partial dentures with different double crowns. Clin Oral Investig 22:1641-1649

10. Yi YJ, Cho LR, Park CJ (2003) Cause of technical failures of conical crown-retained denture (CCRD): a clinical report. J Korean Acad Prosthodont 41:714-719

11. Glantz PO (1984) Intraoral behaviour and biocompatibility of gold versus non precious alloys. J Biol Buccale 12:3-16

12. Skirbutis G, Dzingute A, Masiliūnaite V, Šulcaite G, Žilinskas J (2018) PEEK polymer's properties and its use in prosthodontics. A review. Stomatologija 20:54-58

13. Merk S, Wagner C, Stock V, Eichberger M, Schmidlin PR, Roos M, Stawarczyk B (2016) Suitability of secondary PEEK telescopic crowns on zirconia primary crowns: the influence of fabrication method and taper. Materials 9:908

14. Stock V, Schmidlin PR, Merk S, Wagner C, Roos M, Eichberger M, Stawarczyk B (2016) PEEK primary crowns with cobalt-chromium, zirconia and galvanic secondary crowns with different tapers-a comparison of retention forces. Materials 9:187

15. Wagner C, Stock V, Merk S, Schmidlin PR, Roos M, Eichberger M, Stawarczyk B (2018) Retention load of telescopic crowns with different taper angles between cobalt-chromium and polyetheretherketone made with three different manufacturing processes examined by pull-off test. J Prosthodont 27:162-168 
16. Heimer S, Schmidlin PR, Roos M, Stawarczyk B (2017) Surface properties of polyetheretherketone after different laboratory and chairside polishing protocols. J Prosthet Dent 117:419-425

17. Bathala L, Majeti V, Rachuri N, Singh N, Gedela S (2019) The role of polyether ether ketone (PEEK) in dentistry - a review. J Med Life 12:5-9

18. Luft V, Pospiech P, Schurig A, Schmitter M (2021) In vitro investigations on retention force behavior of conventional and modern double crown systems. Dental Mater 37:191-200

19. Schwindling FS, Stober T, Rustemeier R, Schmitter M, Rues S (2016) Retention behavior of double-crown attachments with zirconia primary and secondary crowns. Dent Mater 32:695-702

20. Engels J, Schubert O, Güth JF, Hoffmann M, Jauering C, Erdelt K, Stimmelmayr M, Beuer F (2013) Wear behavior of different double-crown systems. Clin Oral Investig 17:503-510

21. Besimo CH, Graber G, Flühler M (1996) Retention force changes in implant-supported titanium telescope crowns over long-term use in vitro. J Oral Rehabil 23:372-378

22. Brunner E, Domhof S, Langer F (2012) nparLD: nonparametric analysis of longitudinal data in factorial experiments, $\mathrm{R}$ package version 2.1

23. R Core Team (2019). R: a language and environment for statistical computing. R Foundation for Statistical Computing, Vienna, Austria. URL https://www.R-project.org/.

24. Arnold C, Schweyen R, Boeckler A, Hey J (2020) Retention force of removable partial dentures with CAD-CAM-fabricated telescopic crowns. Materials 13:3228

25. Shimakura M, Nagata T, Takeuchi M, Nemoto T (2008) Retentive force of pure titanium konus telescope crowns fabricated using CAD/CAD system. Dent Mater J 27:211-215

26. Arnold C, Hey J, Schweyen R, Setz JM (2018) Accuracy of CADCAM-fabricated removable partial dentures. J Prosthet Dent 119: 586-592

27. Yoshikawa Y, Torii K, Tanaka M (2019) Influence of the number of insertions and removals of telescopic zirconia/alumina crowns on retentive force and settling. Dent Mater 38:671-677

28. Bayer S, Zuziak W, Kraus D, Keilig L, Stark H, Enkling N (2010) Conical crowns with electroplated gold copings: retention force changes caused by wear and combined off-axial load. Clin Oral Implants Res 22:323-329
29. Beschnidt SM, Chitmongkolsuk S, Prull R (2001) Telescopic crown-retained removable partial dentures: review and case report. Compend Contin Educ Dent 22:927-934

30. Beuer F, Edelhoff D, Gernet W, Naumann M (2010) Parameters affecting retentive force of electroformed double-crown systems. Clin Oral Investig 14:129-135

31. Elkabbany A, Kern M, Elkhadem AH, Wille S, Amer AA, Chaar MS (2020) Retention of metallic and non-metallic double-crownretained mandibular overdentures on implants: an in-vitro study. J Prosthodont Res 64:384-390

32. Bayer S, Kraus D, Keilig L, Gölz L, Stark H, Enkling N (2012) Changes in retention force with electroplated copings on conical crowns: a comparison of gold and zirconia primary crowns. Int $\mathbf{J}$ Oral Maxillofac Implants 27:577-585

33. Nakagawa S, Torii K, Tanaka M (2017) Effects of taper and space setting of telescopic Ce-TZP/A crowns on retentive force and setting. Dent Mater 36:230-235

34. Fischer CAI, Ghergic DL, Vranceanu DM, Ilas SA, Comaneanu RM, Baciu F, Cotrut CM (2020) Assessment of force retention between milled metallic and ceramic telescopic crowns with different taper angles used for oral rehabilitation. Materials (Basel) 13: 4814

35. Yabul A, Dayan C, Geckili O, Bilhan H, Tuncer N (2018) Evaluation of volumetric wear of abutments on the retention loss of ball attachment systems in implant-retained overdentures: an in vitro study. Clin Implant Dent Relat Res 20:778-784

36. Zierden K, Kurzrock L, Wöstmann B, Rehmann P (2018) Nonprecious alloy vs precious alloy telescopic crown-retained removable partial dentures: survival and maintenance needs. Int J Prosthodont 31:459-464

37. Stawarczyk B, Taufall S, Roos M, Schmidlin PR, Lümkemann N (2018) Bonding of composite resins to PEEK: the influence of adhesive systems and air-abrasion parameters. Clin Oral Investig 22:763-771

Publisher's note Springer Nature remains neutral with regard to jurisdictional claims in published maps and institutional affiliations. 